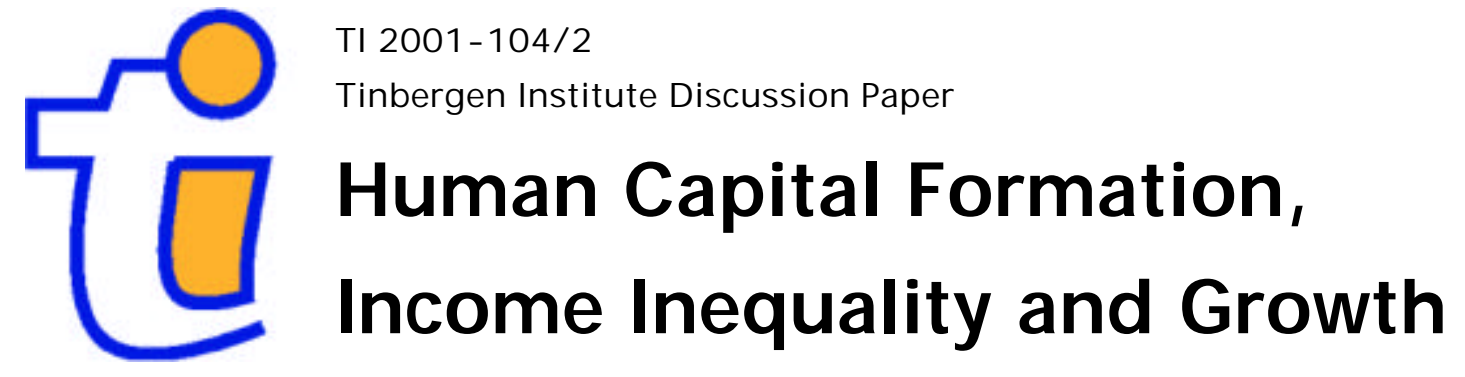

\author{
Jean- Marie Viaene1,2 \\ Itzhak Zilcha3,2
}

\footnotetext{
1 Department of General Economics, Faculty of Economics, Erasmus University Rotterdam, 2 Tinbergen Institute,

3 The Eitan Berglas School of Economics, Tel Aviv University
} 
Tinbergen Institute

The Tinbergen Institute is the institute for economic research of the Erasmus Universiteit Rotterdam, Universiteit van Amsterdam and

Vrije Universiteit Amsterdam.

Tinbergen I nstitute Amsterdam

Keizersgracht 482

1017 EG Amsterdam

The Netherlands

Tel.: +31.(0)20.5513500

Fax: $\quad+31 .(0) 20.5513555$

Tinbergen Institute Rotterdam

Burg. Oudlaan 50

3062 PA Rotterdam

The Netherlands

Tel.: $\quad+31 .(0) 10.4088900$

Fax: $\quad+31 .(0) 10.4089031$

Most TI discussion papers can be downloaded at

http://www.tinbergen.nl 


\title{
Human Capital Formation, Income Inequality and Growth*
}

\author{
J ean-M arie Viaene \\ E rasmus University and T inbergen Institute R otterdam \\ Itzhak Zilcha \\ The Eitan B erglas School of E conomics, Tel A viv University
}

November 9, 2001

\begin{abstract}
A bstract
The paper studies the determinants of income distribution and growth in an overlapping generations economy with heterogenous households. Our framework has the following main features: (1) heterogeneity of consumers with respect to wealth and parental human capital; (2) intergenerational transfers, accomplished via investment in the education of the younger generation. Heterogeneity in income results from the distribution of human capital across individuals in a nondegenerate way. The human capital production is axected by 'homeeducation', provided by the parents, as well as 'public-education' which is provided equally to all young individuals of the same generation. Due to investments in human capital our economy exhibits endogenous growth. First, we explore the exects of technological change in human capital formation, upon the distribution of income at each date along the equilibrium path. Second, we study the impact of such technogical progress on growth and relate these results to the income distribution inequality. Third, we provide numerical simulations to quantify the exect of changes in the parameters of the model. Simulation results include exact $G$ ini coec cients and tax rate on labor determined endogenously through majority voting.
\end{abstract}

J EL classi..cation: D9; E2; F2; J 2 
K eywords: Human Capital; Income Distribution; Endogenous Growth

A ddresses for Correspondence:

J.-M. Viaene, Faculty of Economics, H8-8, E rasmus University, P.O. B ox 1738, 3000 DR Rotterdam, the Netherlands; phone: (+31)-10-4081397; Fax: (+31)-10-4089146; email: viaene@few.eur.nl

I. Zilcha, The Eitan Berglas School of Economics, Tel-Aviv University, Ramat A viv 69978 Israel; Phone (+972)-3-6409913; fax (+972)-3-6409908; email: izil@post.tau.ac.il

*We are grateful to the participants of the CE Sifo conferences on "G rowth and I nequality: Issues and Policy Implications" for contributing remarks. We also wish to express our thanks to T. Eicher, H. de Kruijk, R. Riezman, H.W. Sinn, O. Swank and S. Turnovsky for numerous suggestions. Research assistance by $\mathrm{D}$. Ottens is gratefully acknowledged. 


\section{Introduction}

It is well established in many studies by economists (and sociologists) that education plays a signi..cant role in shaping the income distribution and the growth process. We observe in recent decades increasing awareness of governments in the education process and, consequently, in enhancing investments to promote human capital skills. In recent years, as the information technology advances and computors are being integrated into the learning technology, we are witnessing some important technological progress in the process of human capital formation. In this paper we shall investigate the exects of various kinds of technological improvements on growth and the intragenerational distribution of income.

Education/training lies in the heart of our model and it is composed of two parts: The parental role which takes place at 'home', mainly during the period of 'youth', and the 'out of home' schooling, or the 'public part' which, in most cases, is provided by the government and infuenced by the 'environment'. Home education is provided by the close family and it is carried out through parental tutoring, social interaction, learning devices available at home (such as computors), etc. In this case the human capital of parents and the time they dedicate to teaching/ tutoring play an important role. The government in our education process has two main tasks: First, in organizing the public provision of education and determining the 'level' of public schooling and, second, in ..nancing the public provision of education via taxes on wage income. We shall not attempt in this paper, except in our numerical simulations, to study the process which determines the 'level of public schooling', but rather take it as given in each period. Clearly, given the initial distribution of human capital (and of income) some democratic process will lead to certain decisions, based on the principle that education is provided equally to the younger generation, while the taxes paid by each individual to ..nance public education depend on his level of income.

We consider an overlapping generations economy which produces a single good using two types of production factors: physical capital and human capital. It starts at date 0 with some given initial distribution of human capital and physical capital stock. Due to investments in human capital of the younger generation, the economy exhibits endogenous growth. Each individual lives for three periods: the 'youth' period in which no economic 
decisions are made but education is acquired, the 'working period' where this individual earns wage income, and the 'retirement period' in which only consumption takes place. Intergenerational transfers in our economy take place only in the form of investment, made by parents, in educating their oxspring and in the provision of public education.

When looking at the exects of technological changes in human capital formation we ..nd that in some cases a more equal intragenerational income distribution coincides with higher output, while in other cases certain technological improvements enhance growth but make income distribution less equal. Basically, an important result of this work is to point out that the way in which technological progress axects the process of human capital accumulation matters. If improvements occur mainly in 'home-education' we ..nd that growth increases while inequality in income distributions increases. On the other hand, when the technological improvement axects mostly 'public-education' then we witness higher growth but less inequality in income distribution.

The remainder of the paper is organized as follows. The next section reviews some related literature. Section 3 presents a process of human capital formation which is part of an OLG model with altruistic heterogenous agents and characterizes the equilibrium of a closed economy. Numerical simulations illustrate the properties of the model. Section 4 studies and simulates the exects of changes in educational technology and externalities on growth and intragenerational income distributions. Section 5 presents numerical simulations of our dynamic general equilibrium model when majority voting determines the level of public schooling. Section 6 discusses the main results of the paper and the A ppendix contains proofs to facilitate the reading.

\section{Related Literature}

Endogenous growth models have attracted tremendous attention in economics in the last two decades. As was demonstrated in various ways in the literature they provide an extremely ed cient analytical tool in studying issues related to growth, convergence and distribution of income in equilibrium [see, e.g., Loury (1981), Becker and Tomes (1986), Lucas (1988), A zariadis and Drazen (1990), Tamura (1991), Glomm and Ravikumar (1992), E ckstein 
and Zilcha (1994), Fischer and Serra (1996), Eicher (1996), Fernandez and Rogerson (1998), van Marrewijk (1999), Galor and M oav (2000), Viaene and Zilcha (2001)]. A central feature in all these studies is the way in which the evolution process of human capital is modelled. This process is complex since the accumulation of human capital or skills depends not only on parents, the 'environment', teachers, schools and investment in education, but also on technology and culture. However, the production function for human capital used in economic models concentrate, for tractability reasons, on very few parameters [see, e.g., J ovanovic and Nyarko (1995)]. Like that part of the literature, production in our framework is constrained by education and work experience. Our model in the stationary state is an AK-type endogenous growth model where all variables grow at the same rate as exective labor. The advantage of our OLG framework is that, in contrast to the existing literature, it allows for a comparison, period by period, of non-stationary competitive equilibria.

Statistical oф ces of international organizations compile extensive lists of indicators that describe and compare educational achievements across countries [see, e.g., OECD (1997)]. While these features vary from country to country and thus there may not be a single theory that characterizes all the observed developments, two main common elements have inspired our framework of analysis. First, the production function for human capital exhibits the property that individuals from a below-average families have a greater return to human capital investment derived from public schooling than those from above-average human capital families. Also, the exort, and therefore cost, of acquiring human capital for the younger generation is smaller for societies endowed with relatively higher levels of human capital [see, e.g., Tamura (1991), Fischer and Serra (1996)]. Second, parental tutoring plays an important role. For example, Glaeser (1994) divides the education's positive exects on economic growth into parts, and concludes that children in families with educated parents seem to obtain a better education than do those children without that supportive context. A Iso, Burnhill et al. (1990) ..nd that parental education infuences entry to higher education in Scotland over and above the infuence of parental social class. A reason which is put forward is that parental education elicits more parental involvement at home. A $n$ important dixerence between our process of human capital accumulation and most cases discussed in the literature is the representation of private and public inputs via time in the production of human capital. Our 
approach suggests that the time spent learning, coupled with the human capital of the instructors, and not the expenditures on education should be the relevant variables in this process. This distinction is important since in a dynamic framework the cost of ...nancing a particular level of human capital łuctuates with relative factor rewards.

There is some analogy between the objectives of our paper and those analyzed in Eicher (1996). The latter looks at the endogenous absorption of new technologies into production on endogenous growth and the wage of skilled relative to non-skilled labor. While technological change is exogenous in our model, we have a continuum of skills which provides insights into how technological change in $\ddagger$ uences the equilibrium income distribution, partly through incentives to acquire human capital. Unlike Eicher (1996), individuals do not invest in their own human capital. W ith compulsory schooling in mind, it seems that the acts of training are not fully decided by the young generations.

Income distribution is another key economic issue and its importance is forcing economists and policymakers to improve their understanding of its underlying determinants. Evidence of a rise in income inequality has been observed in a large number of OECD countries. Some believe that social norms are crucial determinants of earnings inequality [e.g., Atkinson (1999), Corneo and J eanne (2001) ]. In contrast, there is a widely held belief that this rise is driven by events like progress in information technology, integration of world trade and ..nancial markets. The role of human capital accumulation on income distribution was thoroughly studied by many researchers in various contexts [see, e.g., Loury (1981), Becker and Tomes (1986), Galor and Zeira (1993), Fernandez and Rogerson (1998), Viaene and Zilcha (2001)]. Others have shown great interest in the impact of income inequality on economic systems. For example, it was shown by Glomm and Ravikumar (1992) that majority voting results in a public educational system as long as the income distribution is negatively skewed. Cardak (1999) strenghens this result by considering a voting mechanism where the median preference for education expenditure, rather than median income household, is the decisive voter. There is also the popular claim that income inequality is harmful to economic growth. Some empirical ..ndings indicate indeed that the conjecture of a negative exect holds [see, e.g. Persson and Tabellini (1994)]. M ore recent evidence dixers, however, depending on the sample period, on the 
sample of countries and on whether time-series or cross-section estimation techniques are used [see, e.g., Forbes (2000)], a fact which is also obtained in our theoretical work.

\section{The M odel}

\subsection{Human Capital Formation}

Consider an overlapping generations economy with a continuum of consumers in each generation, each living for three periods. During the ..rst period each child gets education, but takes no economic decision. Individuals are economically active during a single working period which is followed by the retirement period. At the beginning of the 'working period', each parent gives birth to one oxspring. An agent is characterized by his/her family name ! $2[0 ; 1]$, population is normalized to unity. Denote by - the set of families in each generation: - is time independent since we assume no population growth. Denote by ${ }^{1}$ the Lebesgue measure on - :

A gents are endowed with two units of time in their second period: one is inelastically supplied to the labor market while the other is allocated between leisure and time invested in generating human capital of the oxspring. The motivation for parental tutoring is the utility parents derive from the future lifetime income of their child. Besides self-educating their own child, parents also pay (by taxes) for formal education, to enhance the human capital of their child. Consider generation t, i.e., all individuals ! born at the outset of date $t$, denoted $G_{t}$, and denote by $h_{t+1}(!)$ the level of human capital of family !'s child: We assume that the production function for human capital is composed of two components: informal education provided by the parents and public education provided by 'teachers' and the social environment. Informal education depends on the time allocated by the parents to this purpose, denoted by $e_{(}(!)$, and the 'quality of tutoring' represented by the parent's human capital level $h_{t}(!)$. The time allocated to schooling by the public education system is denoted by $e_{g t}$, and we assume that the human capital of the teachers determine the 'quality' of this contribution to the formation of human capital. We assume that, for some constants ${ }^{-}{ }_{1}>1$; ${ }_{2}>1 ; \dot{A}>0$ and '>0; a family's human capital evolves as follows:

$$
h_{\mathrm{t}+1}(!)={ }^{-}{ }_{1} \mathrm{e}(!) \mathrm{h}_{\mathrm{t}}^{\dot{A}}(!)+{ }^{-}{ }_{2} \mathrm{e}_{\mathrm{gt}} \bar{h}_{\mathrm{t}}^{\prime}
$$


where the average human capital of 'teachers' is the average human capital of generation $t$, denoted $\bar{h}_{t}$. This can be justi..ed if we assume that the individuals engaged in education in each generation, called 'teachers', are chosen randomly from the population of that generation. The parameters À and ' measure the intensity of the externalities derived from parents' and society's human capital respectively. The constants ${ }^{-}{ }_{1}$ and ${ }_{2}{ }_{2}$ represent the ed ciency of informal and formal education: ${ }_{1}$ is axected by the home environment while ${ }_{2}{ }_{2}$ is axected by facilities, the schooling system, the neighborhood, social interactions, organization, etc. A similar human capital formation process to this one has been used in Eckstein and Zilcha (1994).

The assumption that teachers have the average level of human capital has a number of implications for our analysis. On the one hand, it allows a feedback to occur between the rest of the model and teacher quality, an element of complication. On the other hand, it leads to a simpli..cation in that the tax rate on labor is equal to time allocated to schooling by the public education. To see that, consider the lifetime income of individual ! , denoted by $y_{t}(!)$. Since the human capital of a worker is observable and constitutes the only source of income, it depends on the exective labor supply:

$$
y_{t}(!)=w_{t}\left(1 ; i_{t}\right) h_{t}(!)
$$

where $w_{t}$ is the wage rate in period $t$ and $i_{t}$ is the tax rate on labor income. ${ }^{1}$ Under the public education regime taxes on incomes ..nance the costs of educating the young generation. Making use of (1) and (2), balanced government budget means:

$$
{ }^{Z} w_{t} e_{g t} h_{t} d^{1}(!)={ }^{Z}{ }_{i t} w_{t} h_{t}(!) d^{1}(!)
$$

or equivalently,

$$
e_{g t}=i_{t}
$$

that is, the tax rate on labor is equal to the proportion of the economy's exective labor used for public education. ${ }^{2}$

\footnotetext{
${ }^{1} T$ he heterogeneity of consumers stems from the heterogeneity of income. As $w_{t}$ and it are common to all agents, (2) clearly indicates that heterogeneity of incomes derives from the distribution of human capital across individuals.

${ }^{2}$ In contrast, under a decentralized system, both $i t_{t}(!)$ and $e_{g t}(!)$ are decision variables
} 


\subsection{Equilibrium}

Production in this economy is carried out by competitive...rms that produce a single commodity, using exective labor and physical capital. This commodity serves for consumption and also as an input in production. There is a full depreciation of the physical capital. The per-capita human capital in date $t$, $h_{t}$, (not including the human capital devoted to formal education) is an input in the production process. In particular we take the aggregate production function to be:

$$
q=F\left(k_{t} ;\left(1 ; e_{g t}\right) h_{t}\right)
$$

where $k_{t}$ is the capital stock and $\left(1 ; e_{g t}\right) h_{t}=\left(\begin{array}{ll}1 & i t\end{array}\right) h_{t}$ is the exective human capital used in the production process. $F(\phi \Phi$ is assumed to exhibit constant returns to scale, it is strictly increasing, concave, continuously dixerentiable and satis..es $F_{k}\left(0 ;(1 ; i t) h_{t}\right)=1 ; F_{h}\left(k_{t} ; 0\right)=1$; $F\left(0 ;\left(1 ; \quad i_{t}\right) h_{t}\right)=F\left(k_{t} ; 0\right)=0$ : Given this, agent ! at time t maximizes the following lifetime utility:

$$
\left.\left.\max _{\Theta ; S t} u_{t}(!)=c_{1 t}(!)^{\circledR_{1}} c_{2 t}(!)\right)^{\Theta_{2}} y_{t+1}(!)\right)^{a_{3}}[1 ; \quad e(!)]^{\Theta_{4}}
$$

subject to

$$
\begin{gathered}
c_{1 t}(!)=y_{t}(!) ; s_{t}(!), 0 \\
c_{2 t}(!)=\left(1+r_{t+1}\right) s_{t}(!) \\
w_{t}=F_{h}\left(k_{t} ;\left(1 ; e_{g t}\right) h_{t}\right)
\end{gathered}
$$

of agents and the individual's budget constraint on private education is:

$$
i_{t}(!) w_{t} h_{t}(!)=w_{t} e_{g t}(!) \bar{h}_{t}
$$

where the level of teachers' instruction is chosen freely from the market but their average human capital is the same as the economy's. Aggregate resources invested in education then become:

$$
\text { Z } e_{g t}(!) d^{\mathrm{p}}(!)={\frac{1}{\overline{h_{t}}}}^{Z} \text { ¿ } i t(!) h_{t}(!) d^{\mathrm{p}}(!) \text {; }
$$

which depend upon the distribution of human capital in each date. This is not the case under public education. 


$$
\begin{aligned}
\left(1+r_{t}\right) & =F_{k}\left(k_{t} ;\left(1 ; e_{g t}\right) h_{t}\right) \\
k_{t+1} & ={ }^{Z} s_{t}(!) d^{1}(!)
\end{aligned}
$$

where income $\mathrm{y}_{\mathrm{t}}(!)$ is de..ned by (2) and human capital $\mathrm{h}_{\mathrm{t}+1}(!)$ is given by (1). The $\mathbb{R}_{9} S$ are known parameters and $\mathbb{Q}>0$ for $\mathrm{i}=1 ; 2 ; 3 ; 4 ; \mathrm{c}_{1 t}(!)$ and $c_{2 t}(!)$ denote, respectively, consumption in ..rst and second period of the individual's life; $s_{t}(!)$ represents savings; leisure is given by $(1 ; \mathrm{e}(!))$; $\left(1+r_{t}\right)$ is the interest factor at date t. The oxspring's income, given by $y_{t+1}(!)$; enters parents' preferences directly and represents the motivation for parents' tutoring and formal education expenditure. Eq. (6) is individual ! 's budget constraint. Eqs. (8) and (9) are the clearing conditions on factor markets. Condition (10) is a market clearing condition for physical capital, equating the aggregate capital stock at date $t+1$ to the aggregate savings at date t:

A fter substituting the constraints, the ..rst-order conditions that lead to the necessary and suф cient conditions for optimum are:

$$
\begin{aligned}
& \frac{C_{1 t}}{C_{2 t}}=\frac{\mathbb{R}_{1}}{\mathbb{R}_{2}\left(1+r_{t+1}\right)}
\end{aligned}
$$

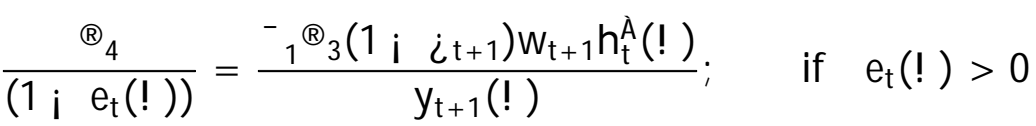

$$
\begin{aligned}
& \text { if } \quad e_{t}(!)=0 \text { : }
\end{aligned}
$$

The last equation allocates the unit of non-working time between leisure and the time spent on education by the parents. The latter, e(! ); increases with the parents' human capital $h_{\mathrm{t}}^{\hat{A}}$ and the wage, net of taxes, at the future date. Eq. (12) establishes a negative relationship between types of education, that is, public education substitutes for parental tutoring as $i t+1$ increases. Hence, for each individual there exists a particular value of the tax rate such 
that $e_{(}(!)=0$. This is obtained when the marginal utility of leisure is larger than the net future wage received from a marginal increase in the human capital of the younger generation as a result of parental tutoring. From (6), (7) and (11) we also obtain:

$$
\begin{aligned}
& C_{1 t}(!)=\frac{\mu}{\mathbb{B}_{1}+\mathbb{B}_{2}} y_{t}(!) \\
& S_{t}(!)=\frac{\mu}{\mathbb{B}_{1}+\mathbb{R}_{2}} y_{t}(!)
\end{aligned}
$$

It is useful to derive the evolution of human capital from the ..rst order conditions. Making use of (12), the human capital of a dynasty given by (1) can be rewritten as follows:

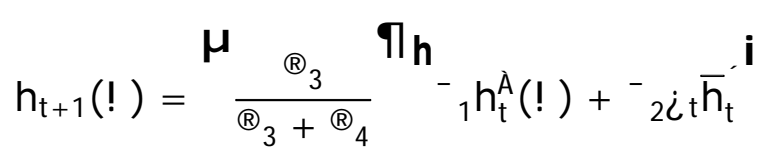

De. ne the growth factor of aggregate labor as:

$$
\circ_{t}, \frac{h_{t+1}}{h_{t}}, \frac{s_{-} h_{t+1}(!) d^{1}(!)}{s_{-} h_{t}(!) d^{1}(!)}
$$

Substitution of (16) in (17) gives us an alternative expression for ${ }_{t}{ }_{t}$ :

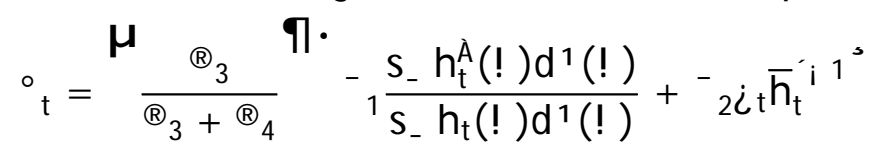

It is clear from (18) that the growth factor of exective labor is the sum of two terms, one representing the contribution of parental tutoring, the other the contribution of public education. While the latter is in₹uenced by the tax rate the former depends upon the distribution of human capital at each date.

\subsection{Numerical Simulations}

The aim of this section is to introduce a dynamic computable general equilibrium model with heterogenous agents and to characterize the properties of the equilibria of the model discussed so far. In particular, we are interested 
in establishing the relationship between changes in some parameters, and the growth and distribution of income that can be sustained in equilibrium. To facilitate the interpretation of our theoretical results the ..rst set of numerical simulations assume that the sequence of $i t$ is exogenously given. Later in Section 5, we allow for the tax rate to be endogenously determined through majority voting.

In our numerical examples we replace (4) by the Cobb-Douglas production

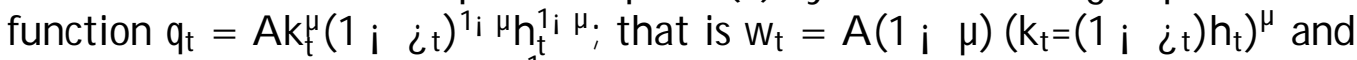
$\left(1+r_{t}\right)=A \mu\left(\left(\begin{array}{ll}1 & i_{t}\end{array}\right) h_{t}=k_{t}\right)^{I_{i} \mu}:$ In the baseline case, we assume that the economy is in a steady-state. To characterize the latter, consider Eqs. (2); (10), (15) and the Cobb-Douglas production function to obtain:

$$
\frac{k_{t+1}}{k_{t}}=\frac{(1 ; \mu) \mathbb{R}_{2}}{\mu\left(\mathbb{B}_{1}+\mathbb{R}_{2}\right)}\left(1+r_{t}\right)
$$

Making use of (17) and of the expression for the rental rate:

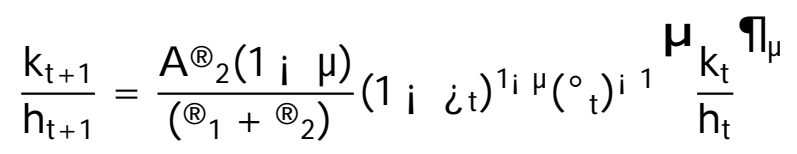

which describes the dynamic path of the capital-labor ratio of the economy. In the long-run $\mathrm{k}_{\mathrm{t}+1}=\mathrm{h}_{\mathrm{t}+1}=\mathrm{k}_{\mathrm{t}}=\mathrm{h}_{\mathrm{t}}$ is a constant $\mathrm{k}=\mathrm{h}$ if $\mathrm{it}_{\mathrm{t}}=\dot{i}$ and ${ }^{\circ}{ }_{\mathrm{t}}={ }^{\circ}$ : The time-independence of ${ }^{\circ}$ can be obtained by incorporating externalities that yield constant returns to scale to parents' and society's human capital in (1), namely assuming $\grave{A}={ }^{\prime}=1$ : In that case we obtain the long-run capital-labor ratio from (20):

$$
\frac{k}{h}=(1 ; \quad i){\frac{\mathbb{R}_{2}(1 ; \mu) A}{{ }^{\circ}\left(\mathbb{R}_{1}+\mathbb{R}_{2}\right)}}^{\frac{{ }^{1}}{(1 ; \mu)}}
$$

From the above equations, we obtain the expression for long-run output and income growth:

$$
\frac{q_{t+1}}{q}=\frac{{ }_{R} y_{t+1}(!) d^{1}(!)}{-y_{t}(!) d^{1}(!)}=\frac{\mathbb{R}_{2}(1 ; \mu) A}{\left(\mathbb{R}_{1}+\mathbb{R}_{2}\right)} \frac{\mu}{h(1 ; i)}^{q_{1_{i} \mu}}
$$

Substituting (21) in this last expression gives:

$$
\frac{q+1}{q}=0
$$


Long-run economic growth coincides with the growth factor of exective labor $\left({ }^{\circ}\right)$; regardless of initial conditions. Our model in the stationary state is therefore an AK-type endogenous growth model where all variables grow at the rate $\left({ }^{\circ} ; 1\right)$ :

Besides $\grave{A}={ }^{\prime}=1$; we assume that the other baseline parameters are $\mathrm{k}_{\mathrm{i} 1}=70: 019 ; i=0: 2 ; \mathbb{B}_{1}=\mathbb{B}_{2}=\mathbb{\circledR}_{4}=1 ; \mathbb{B}_{3}=2 ; \mathrm{A}=4 ; \mu=: 3$ and $^{-}{ }_{1}=$ ${ }_{2}=1: 6$ : We consider a discrete number of heterogenous families, namely 11 , with a human capital at $\mathrm{t}=\mathrm{i} 1$ taking the values $1 ; 2 ; \cdots: 8 ; 11 ; 14 ; 16:$ The initial endowments in physical and human capital were chosen with three criteria in mind. First, the values of the endogenous variables that follow from these initial conditions and parameter values are long-run values at all dates. Second, the initial heterogeneity in human capital calibrates an exact Gini coed cient close to the European average, namely 0.309 in period 0 . Third, the distribution of human capital is negatively skewed, a fact which is observed in many countries. The median lies therefore to the left of the mean. The following formula for the Gini coet cient is used:

$$
g=\frac{1}{2 n^{2} y_{t}} x_{i=1}^{n} x_{j=1}^{n} j y_{i} i \quad y_{j} j
$$

where $n$ represents the number of families, $y_{t}$ is average income, $y_{i}$ and $y_{j}$ are individual incomes.

Given the set of baseline parameters of the model, the equilibrium path of all variables belonging to a particular family is obtained in two steps. First, the human capital of any individual at date $t$ is given by (16). Aggregating the levels of human capital across individuals and equating the aggregate capital stock at date t to the aggregate savings at date $t$ i 1 (see (10)), we obtain aggregate production $q_{\text {; }}$ the equilibrium $w_{t}$ and $\left(1+r_{t}\right)$ : Upon this information, each individual derives his/her income $y_{t}(!)$ from (2) and summary statistics like the Gini coed cient can be computed. Second, given the time path of wages, marginal returns to physical capital and income of each dynasty, each individual can compute $\mathrm{e}_{t}(!) ; \mathrm{c}_{1 t}(!)$; $\mathrm{c}_{2 t}(!)$; and $\mathrm{u}_{\mathrm{t}}(!)$ :

\section{[Insert Table 1]}

Table 1 presents the solution for our baseline case and the equilibrium corresponding to a $10 \%$ increase in each parameter of the utility function. 
Changes in other parameters are emphasized in the next section. In the numerical simulations, given the chosen parameters we solve the model for 200 periods. As patterns emerge within 20 periods we discard the last 180 periods and compute the relevant statistics averaging over the ..rst 10 periods and over the second 10 periods.

A feature of the baseline is the decreasing inequality among dynasties. Though families start in period 0 with very dixerent endowments, they tend to be similar after 20 periods. This shows the strength of public education relative to parental tutoring in the accumulation of human capital. This result is obtained even though families have dixerent degrees of parental tutoring as indicated by the last two rows. Changes in the parameters of the utility function do not axect the income distribution results. Though they modify individual incomes, the latter are modi..ed altogether in the same proportion as they all share the same utility function. Results in columns (2) and (3) can be best explained by referring to (14) and (15). W hile an increase in $\mathbb{B}_{\mathbb{1}}$ is conducive to less savings and more current consumption, an increase in $\mathbb{B}_{2}$ leads to the reverse. W hile an increase in ${ }_{\mathbb{1}}$ leads to somewhat lesser growth in the short-run and higher rental rates when compared to baseline, the opposite occurs in column (3). Columns (4) and (5) contrast stronger altruistic preferences with stronger preferences for leisure respectively. It is important to note the marked dixerences in growth rates and parental education. M ore altruism leads to higher levels of human capital via more parental exorts in education and ultimately to higher long-run growth rates. The opposite occurs with a higher $\mathbb{B}_{4}$ :

\section{Income Distribution and Growth}

The focus of this section is to consider the inequality in the intragenerational income distribution, in equilibrium, and relate it to the various parameters of our dynamic model. At the same time, we wish to explore the relationship between inequality and growth. Our explanation will be based on the extent of ed ciencies and externalities in the process of human capital accumulation.

We shall use the relations that we derived in the previous section to obtain an expression for income at date $t+1, y_{t+1}(!)$ : To that end isolate $y_{t+1}(!)$ 
in (13) and make use of (1), (2) and (3) to obtain:

$$
y_{t+1}(!)=\frac{\mu}{\mathbb{B}_{3}+\mathbb{B}_{4}}{ }^{~}\left(1 ; \quad i_{t+1}\right) w_{t+1}{ }^{-}{ }_{1} h_{t}^{\dot{A}}(!)+{ }^{-}{ }_{2} e_{g t} \bar{h}_{t}^{, i}
$$

Eq. (23) determines income at the future date in terms of the net wage at date $t+1$; the parents' and society's level of human capital at date t; the current education input $\left(i_{t}=e_{g t}\right)$ and the externalities in education. Note that in this framework there is no direct dependence of incomes across generations.

We shall use a de. nition to compare distribution functions. Let $X$ and $W$ be two random variables with values in a bounded interval in $(i 1 ; 1)$ and let $m_{x}$ and $m_{w}$ denote their respective means. De. ne $X=X=m_{x}$ and $\mathbb{N}=\mathrm{W}=\mathrm{m}_{\mathrm{w}}$ : Denote by $\mathrm{F}_{\mathrm{x}}$ and $\mathrm{F}_{\mathrm{w}}$ the cumulative distribution functions of $\chi$ and $\mathbb{W}$; respectively. Let [a; $b$ ] be the smallest interval containing the

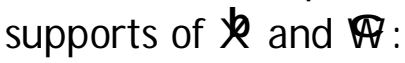

De.nition: $F_{X}$ is more equal than $F_{w}$ if, for all t 2 [a; b];

$\mathrm{R}_{\mathrm{a}}\left[\mathrm{F}_{\mathrm{x}}(\mathrm{s}) \mathrm{i}\right.$ $\left.F_{w}(s)\right] d s \cdot 0:$

Thus, $F_{X}$ is more equal than $F_{W}$ if $F_{X}$ dominates in the second-degree stochastic dominance $F_{w}:$ This de. nition, due to Atkinson (1970), is equivalent to the requirement that the Lorenz curve corresponding to $X$ is everywhere above that of $\mathrm{W}$ : We say that $\mathrm{X}$ is more equal than $\mathrm{W}$ if the c.d.f. of $X$ and $\mathbb{W}$ satisfy: $F_{x}$ is more equal than $F_{w}$. Henceforth the relation $X$ is more equal than $W$ is denoted $X \dot{A} W$ : We say that $X$ is equivalent to $W$; and denote this relation by $X 1 / 4 W$, if $X \grave{A} W$ and $W \grave{A} X$ :

\subsection{Initial Conditions}

Consider two similar economies which dixer only in the initial distributions of human capital: one economy has higher levels of human capital but the same inequality of human capital distribution. Can we compare the equilibrium intragenerational income distributions of these two economies over time? The next proposition provides an answer.

Proposition 1 Consider two economies which dixer only in their initial human capital distributions, $h_{0}(!)$ and $h_{0}^{\mathfrak{a}}(!)$. Assume that $h_{0}^{\mathfrak{a}}(!)>h_{0}(!)$ 
for all ! , but $h_{0}^{\mathfrak{a}}(!) 1 / 4 h_{0}(!)$, namely, these two distributions have the same level of inequality. Then, the equilibrium from $h_{0}^{a}(!)$ will have less unequal intragenerational income distributions at all dates $t ; t=1 ; 2 ; 3 ; .: .:$ :

\section{Proof. See the Appendix.}

This result indicates that a country that starts with higher levels of human capital, not necessarily more equal, has a better chance to maintain more equality in its future income distributions.

\subsection{Public Education}

Throughout this section we shall assume that public provision of education is determined by the government, say by elections or other social decision mechanism, and it is equal to $e_{g t}$ in date $t$ and ..nanced by taxing labor income at a ..xed rate $i_{t}>0$. In the sequel we shall assume that $v \cdot 1$ and that ' . 1. Let us consider the variation over time of the inequality in the distribution of income.

Proposition 2 If the same tax rate applies to all levels of income, along the equilibrium path the inequality in intragenerational income distribution at date $t+1$ is smaller than the inequality in the distribution of income at date $t$.

\section{Proof. See the Appendix.}

Column (1) of Table 1 indicated already that under the assumption that the tax rate is the same for all levels of income, inequality declines over time. The inequality in income distribution at date $t+1$ is indeed smaller than the inequality in income distribution at date $t$ and in the limit families tend to the same level of human capital and income. Let us show now that a higher provision of public education reduces inequality in the distribution of income in each generation. 
Proposition 3 In the above economy let $h_{0}(!)$ be the initial human capital distribution. Increasing the public provision of education results in less inequality in the intragenerational income distribution in each date.

\section{Proof. See the Appendix.}

This result may not be surprising since public education is provided equally to all young individuals (of the same generation), while it is ..nanced by a $\ddagger$ at tax rate on wage income. However, its importance lies in the fact that it is proved in equilibrium and that it holds in all future periods. It is also clear from (18) that, when $\hat{A}={ }^{\prime}=1$; more public education contributes to a higher long-run growth rate of exective labor.

\section{[Insert Table 2]}

These results are quanti..ed in the two columns of Table 2 where $i t$ takes two values, 0.20 and 0.22 respectively. Besides increasing the long-run growth rate of output and decreasing the inequality in the income distribution, Table 2 con..rms the substitution among education types. Public education crowds out parental tutoring though the elasticity computed at steady state values is about -.1 and thus quite small.

\subsection{E $₫$ ciencies and Externalities}

Consider some technological change that axects the production of human capital. We say that the provision of public education becomes more ed cient if, in the human capital process (1), ${ }_{2}={ }_{1}$ becomes larger without lowering neither ${ }_{1}{ }_{1}$ nor ${ }_{2}{ }_{2}: 3$ We say that the private provision of education becomes more eq cient if, in the process (1), ${ }_{1}={ }_{2}$ becomes larger while neither ${ }_{1}$ nor ${ }^{-}$declines. Likewise, a technological improvement in the production of human capital is said to be neutral if the ratio ${ }_{2}={ }_{1}$ remains unchanged while both parameters increase. Let us consider now the exects of each type

\footnotetext{
${ }^{3}$ There is a growing empirical literature that has given much attention to increased eф ciency of public education on pupils' current and later achievements. One issue that has been highlighted is the causal exect of class size on human capital. For example, Lindahl (2001) ..nds that smaller classes in Sweden generate higher educational attainments.
} 
of technological improvement in the education process on intragenerational income inequality.

Proposition 4 Consider the above economy. A technological improvement in the production of human capital, given by equation (1), results in:

(a) If public provision of education becomes more ed cient the intragenerational distribution of income becomes less unequal in all periods.

(b) If private provision of education becomes more ed cient income inequality becomes larger in all periods.

(c) If the technological improvement is neutral the inequality in income distribution remains unchanged at period 1 but declines for all periods afterwards.

\section{Proof. See the Appendix.}

Let us consider now another type of a change in the "home-component" of the production of human capital and its economic implications in equilibrium. Observe the process represented by (1). Let us vary the parameters $v$ and ', which relate to the role played by human capital of the parents or the 'environment'. Since we assume that $v$. 1 and ' . 1 let us consider the exect that lower values will have on the inequality in income distributions in equilibrium.

Proposition 5 Consider the process of production of human capital given by (1). Then:

(a) Comparing two economies which dixer only in this parameter v; the economy with the lower $v$ will have less inequality in the intragenerational income distribution in all periods.

(b) Comparing two economies which dixer only in the parameter '; the economy with the lower value of ' will have more inequality in the income distribution in all periods.

Proof. See the Appendix.

Let us consider now the exect that technological improvement in the production of human capital will have on output in equilibrium. Consider (1) and remember that we call the ..rst term on the RHS, ${ }_{1}{ }_{1} \mathrm{e}(!) h_{\mathrm{t}}^{\dot{A}}(!)$, the home-component, and the second term, ${ }_{2} \mathrm{e}_{\mathrm{g}} \bar{h}_{\mathrm{t}}$, the public-component. Now we prove: 
Proposition 6 Consider the human capital production process given by (1) and the following types of technological improvements:

(a) Increasing ${ }^{-}$, or increasing $v$ or both, will increase output in all dates.

(b) Increasing ${ }^{-}{ }_{2}$, or increasing ' or both, will result in higher output in all periods.

If we consider the computor-information revolution as a technological improvement in enhancing knowledge, then we ask whether the home-component bene.ts more than the public- component in the formation process of human capital. We believe that computors and internet have enhanced the homeeducation considerably, while schools bene.t. only in a limited manner. The following corollary may provide some explanation to the recent widespread phenomena (mostly during the nineties) that in the OECD countries economic growth is accompanied by increasing inequality in the distribution of income.

Corollary 7 (a) In the following two cases of technological improvement in the home-component we obtain higher economic growth coupled with more inequality in the distribution of income: (i) an increase in ${ }^{-}{ }_{1}$ (ii) an increase in $\mathrm{v}$.

(b) In the following two cases of technological improvement in the publiccomponent we obtain higher economic growth coupled with less inequality in the distribution of income: (i) an increase in ${ }^{-}{ }_{2}$; (ii) an increase in ':

In terms of results, it is remarkable that both cases of technological improvement yield similar predictions on growth but opposite on income distribution. In this regard, Table 3 adds that inequality as measured by Gini coel cients is more sensitive to externalities arising from the home component than from those arising from the public part of human capital formation. Decreasing returns in parents' human capital (column 2) reduce inequality substantially, all individuals becoming equal in the long-run. In contrast substantial income inequality is observed with increasing returns (column 4). ${ }^{4}$ Columns 2 and 4 establish a positive correlation between growth and income

\footnotetext{
${ }^{4}$ Externalities that yield increasing returns to scale to parents' human capital, that is À > 1; have been observed in China [K night and Shi (1996)] and are therefore not a mere theoretical curiosum.
} 
inequality. In column 2 , decreased inequality is obtained at the expense of growth, whether measured in terms of income or human capital (not shown). Vice versa in column 4. In contrast, when looking at changes in "; the correlation between growth and income inequality is negative as indicated in columns 3 and 5 .

\section{[Insert Tables 3 and 4]}

Table 4 looks at a technological improvement in human capital formation represented here by rises in the ${ }^{-q_{5}}$ : Columns 2 to 4 show that a greater et ciency in education is always conducive to growth while hardly axecting income distributions. A comparison of columns 2 and 3 shows the stronger impact that parental education has on output growth.

\section{Majority Voting}

Though there is a growing awareness of governments in education, enhancing human capital skills require ..nancial resources to cover the investment. Though the majority of constituents recognize the importance of learning, they are not prepared to contribute ..nancially via income taxes in the same way. To establish the preferences of each individual with respect to it(!) let us compute the reduced-form utility of each agent. Substituting the ..rst order conditions in (5), lifetime utility of agent ! can be rewritten as:

$$
\begin{aligned}
& u_{t}(!)=-{ }_{t}\left(1 ; i_{t}(!)\right)^{\Theta_{1}+{ }_{2}}\left(1 ; i_{t+1}(!)\right)^{\Theta_{3}} \\
& \left.\left({ }^{-}{ }_{1} h_{t}(!)\right)^{v}+{ }^{-}{ }_{2} i_{t}(!) \bar{h}_{t}^{\prime}\right)^{{ }_{3}+{ }^{B_{4}}}
\end{aligned}
$$

where - $\mathrm{t}$ groups all parameters and variables like factor rewards which are given to atomistic individuals. K nowing that each agent cannot enforce any tax rate at the future date, i.e. $\sum_{t+1}(!)$ is given to him, the maximization of (24) with respect to $i t(!)$ gives:

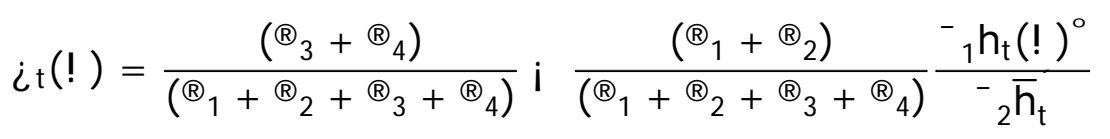


Each agent chooses the optimal $i_{t}(!)$ such that the cost of current spending on education (in terms of foregone current and future consumption) is equal to the reward of a marginal increase in the human capital of their children. It is clear that the heterogeneity in $i_{t}(!)$ derives from the heterogeneity in human capital. When' . 1 and $v$ ' 1 above-average agents are willing to pay a lower tax rate than below-average agents. In terms of numerical results, the ..rst step in our simulations computes a vector of $i_{t}(!)$ based on (25). Given this vector of individual preferences for education expenditure, we assume that the level of public schooling is obtained at each date through majority voting. Numerically, majority voting boils down to identifying the median voter's preference for public schooling.

\section{[Insert Tables 5 and 6]}

Tables 5 and 6 repeat the exercises performed in Tables 3 and 4, now with endogenous public education. What dixerence does it make? Baseline is different because the distribution of human capital being negatively skewed, the median voter's human capital lies to the left of the mean and therefore he/ she wishes a higher tax rate. Tables 5 and 6 reproduce the substitution in equilibrium between public education and parental education observed before: any increase in $i_{t}$ decreases the time spent on parental education $e$ and hence, raises leisure. This substitution among types of provision of education has a number of implications, one of which being that Gini coet cients vary more. It is important to note that simulation results con..rm the robustness of Corollary 7 whose results apply also to the case of endogenous public education. A positive correlation between income inequality and income growth is obtained when externalities or el ciencies arising from parents' human capital vary. In contrast, this correlation is negative when externalities or ed ciencies in the public contribution to human capital are considered.

\section{Discussion}

The paper studies the determinants of income distribution and growth in an overlapping generations economy with heterogenous households. Heterogenity results simply from the distribution of human capital across individuals 
in a nondegenerate way. B oth parental tutoring and public education contribute to human capital accumulation.

In this framework, the following results are derived. (a) Initial conditions matter. For example, a country that starts with higher levels of human capital, not necessarily less equal, has a better chance to maintain less income inequality in the future. Hence, communities which create a culture of literacy and life learning are more likely to experience lower income inequality. (b) There is an important role for public education. Under the assumption that the tax rate that ...nances education is positive and similar for all levels of income, inequality declines over time. Increasing this tax rate in an attempt to enhance the provision of public education results in less income inequality. (c) In our framework a technological change in the aggregate production function has no impact on the distribution of income. Therefore, we consider only technological improvements in the human capital accumulation process. As we show the exect is ambiguous. If improvements occur mainly in home-education, growth increases while inequality in the income distribution increases. In contrast, if technological improvement axects public education then higher growth and less income inequality are obtained. This result creates challenges for policy-makers since independent policies adecting parental education only cannot serve two masters at the same time while those axecting public education can.

Since our model makes some speci..c and simplifying assumptions let us discuss the robustness of our results. First, it is important to note that introducing intergenerational monetary transfers in our model will modify the results: in such a case, technological progress in the aggregate production function may have dixerent exects on the intragenerational income distributions [see K arni and Zilcha (1994)]. Second, the framework can be generalized by introducing an additional redistributive measure by the government, such as social security. This may vary some of our conclusions. Third, our theoretical analysis does not depend on the levels of the public provision of education, $f e_{g t} g$. The choice of some 'optimal' level of public education requires some social welfare function due to the heterogeneity of the households. However, the majority voting criterion is widely used in economic theory, hence, one can determine this level using the median voter's optimal choice. This has been used in our numerical simulations. 


\section{A ppendix}

Proof of Proposition 1. Consider two equilibria in which human capital accumulation is described by (1). Variables under the second equilibrium are marked by "*". Let us rewrite eq. (23) for both equilibria:

$$
\begin{aligned}
& y_{t+1}(!)=C_{t}\left[h_{t}^{\dot{A}}(!)+\frac{-2}{2} e_{g t} \bar{h}_{t}\right] \\
& y_{t+1}^{\alpha}(!)=C_{t}^{\alpha}\left[h_{t}^{\alpha \dot{A}}(!)+\frac{-2}{2} e_{g t} \bar{h}_{t}^{\alpha^{\prime}}\right] \\
& \text { where } C_{t} \text { and } C_{t}^{\alpha} \text { are positive constants. }
\end{aligned}
$$

Since $h_{0}$ and $h_{0}^{\alpha}$ are equally distributed, the same holds for $h_{0}^{v}(!)$ and $\left[h_{0}^{\alpha}(!)\right]^{v}$, since $v \cdot 1$. Moreover, since $\bar{h}_{0}<\bar{h}_{0}^{\alpha}$ we obtain that $h_{1}^{\alpha}(!)$ is more equal than $h_{1}($ !) [again, see Lemma 2 in K arni and Zilcha (1994)]. It is easy to verify from (18) that $h_{1}(!)$ are lower than $h_{1}^{a}(!)$ for all !. In particular we obtain that $\left[h_{1}^{x}(!)\right]^{v}$ is more equal than $\left[h_{1}(!)\right]^{\mathrm{v}}$ [see Theorem 3.A.5 in Shaked and Shanthikumar (1994)]. Also we have $\left[\bar{h}_{1}\right]^{\prime}<\left[\bar{h}_{1}^{\alpha}\right]^{\prime}$. This implies, using (16), that $h_{2}^{a}(!)$ is more equal than $h_{2}(!)$. As in our earlier proofs it is easy to see that this process can be continued to generalize this to all periods. $¥$

Proof of Proposition 2. Let us show ..rst that in each generation individuals with higher level of human capital choose at the optimum higher level of time to be allocated for private education of their oxspring. To see this let us derive from the ..rst order conditions, using some manipulation, the following equation:

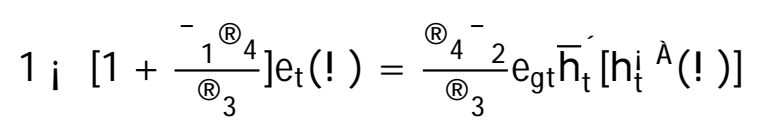

which demonstrates that higher $h_{t}(!)$ implies higher level of e(l!). Let us show that such a property generates less equality in the distribution of $\mathrm{y}_{t+1}(!)$ compared to that of $y_{t}(!)$ : It is useful however, to apply (16) for this issue. In fact it represents the period $t+1$ income $y_{t+1}(!)$ as a function of the date $t$ income $y_{t}($ !) via the human capital evolution. De..ne the function $Q: R$ ! $R$ such that $Q\left[h_{t}(!)\right]=h_{t+1}(!)$ using (16). This monotone increasing function satis..es: $Q(x)>0$ for any $x>0$ and $\frac{Q(x)}{x}$ is decreasing in $x$. Therefore [see, Shaked and Shanthikumar (1994)], the human capital distribution $h_{t+1}(!)$ is more equal than the ditribution in date $t, h_{t}(!)$ : This implies that $y_{t+1}(!)$ is more equal than $y_{t}(!) . ¥$ 
Proof of Proposition 3. Let us consider Eq. (16) for $t=0$ : Since $h_{0}(!)$ is given, $h_{0}^{v}(!)$ and $\bar{h}_{0}$ are ..xed. By raising $e_{g 0}$ the distribution of the human capital for generation $1, h_{1}(!)$ becomes more equal. This follows from Lemma 2 in Karni and Zilcha (1994). Moreover, we claim from (16) that the average human capital in generation 1 increases as well. Increasing ego will result in higher $h_{1}(!)$ for all ! and higher level of $\bar{h}_{1}$. Moreover, it also implies that $h_{1}^{\vee}(!)$ will have a more equal distribution [see, Shaked and Shanthikumar (1994), Theorem 3.A.5].

Now, let us consider $t=1$. Increasing e $e_{11}$ will imply the following facts: $h_{1}^{\vee}(!)$ becomes more equal and ${ }_{2}^{-} e_{g 1} \bar{h}_{1}$ is larger than its value before we increased the levels of public education. Using (16) and the same Lemma as before we obtain that $h_{2}(!)$ becomes more equal. This process can be continued for $t=3 ; 4 ; \ldots .: .:$, which establishes our claim. $¥$

Proof of Proposition 4. Let the initial distribution of human capital $h_{0}(!)$ be given. Compare the following two equilibria from the same initial conditions: One with the human capital formation process given by (1) and another with the same process but ${ }_{2}{ }_{2}$ is replaced by a larger coed cient ${ }_{2}^{-\alpha}>$ ${ }_{2}{ }_{2}$ : Clearly, we keep ${ }^{-}$unchanged. Let us rewrite eq. (23) as follows:

$$
\begin{aligned}
& y_{t+1}(!)=C_{t}\left[h_{t}^{A}(!)+\frac{2}{-2} e_{g t} \bar{h}_{t}\right] \\
& y_{t+1}^{\alpha}(!)=C_{t}^{a x}\left[h_{t}^{a \dot{A}}(!)+\frac{1}{-\frac{n}{p}} e_{g t} \overline{h^{\alpha}}{ }_{t}^{\prime}\right]
\end{aligned}
$$

where $C_{t}$ and $C_{t}^{a}$ are some positive constants. Since $h_{0}(!)$ is ..xed at date $\mathrm{t}=0$ we ..nd [using once again the Lemma from Karni and Zilcha (1994)] that $\frac{-\frac{\pi}{2}}{\frac{1}{1}}>\frac{-2}{\frac{2}{1}}$ imply that $y_{1}^{\sharp}(!)$ is more equal to $y_{1}(!)$. We also derive that $h_{1}(!)$ are lower than $h_{1}^{a}(!)$ for all ! and, hence, $\bar{h}_{1}<\bar{h}_{1}^{\mathbb{\alpha}}$. By (16), using the same argument as, in the last proof, $h_{1}^{\mathrm{av}}(!)$ is more equal than $h_{1}^{\mathrm{v}}(!)$

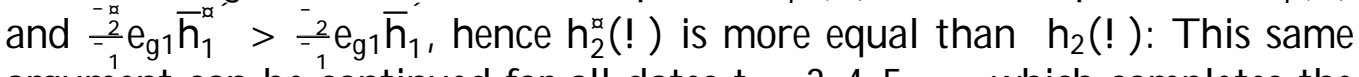
argument can be continued for all dates $t=3 ; 4 ; 5 ;: \ldots::$ : which completes the proof of part (a) of this Proposition. The proof of part (b) follows from the same types of arguments using the fact that if ${ }_{1}<\frac{-\alpha}{1}$ then $\frac{-2}{\frac{1}{1}}>\frac{-\frac{\pi}{2}}{1}$ and, hence, $h_{1}(!)$ is more equal than $h_{1}^{\mathfrak{a}}(!)$ and $\bar{h}_{1}>\bar{h}_{1}^{\mathfrak{\alpha}}$. This process leads, using similar arguments as before, to $y_{t}(!)$ more equal than $y_{t}^{a}(!)$ for all periods t. Consider now the claim in part (c). From (16) we see that inequality in the distribution of $h_{1}(!)$ remains unchanged even though all levels of $h_{1}($ !) increase due to this technological improvement. In particular, $\bar{h}_{1}$ increases. Now, since inequality of $h_{1}^{v}(!)$ did not vary but the second term in the RHS of (16) has increased due to the higher value of $\bar{h}_{1}$, we obtain more equal 
distribution of $h_{2}(!)$. Now, this argument can be used again at dates 3,4 , ...., which completes the proof. $¥$

Proof of Proposition 5. Assume, without loss of generality, that $h_{0}(!), 1$ for all !. Since the two economies have the same initial distribution of human capital $h_{0}(!)$ the process that determines $h_{1}(!)$ dixers only in the parameter $\mathrm{v}$. Denote by $\mathrm{v}^{\mathrm{a}}<\mathrm{v} \cdot 1$ the parameters, then it is clear that $\left[h_{0}(!)\right]^{v^{\sharp}}$ is more equal than $\left[h_{0}(!)\right]^{v}$ since it is attained by a strictly concave transformation [see, Theorem 3.A.5 in Shaked and Shanthikumar (1994)]. Likewise, the human capital distribution $h_{1}^{a}(!)$ is more equal than the ditribution $h_{1}(!)$ : This implies that $y_{1}^{a}(!)$ is more equal than $\mathrm{y}_{1}(!)$. Now we can apply the same argument to date 1 : the distribution of $\left[h_{1}^{a}(!)\right]^{\sharp}$ is more equal than that of $\left[h_{1}(!)\right]^{v}$, hence, using (16) and the above reference, we derive that the distribution of $\left[h_{2}^{a}(!)\right]^{v^{\mathbb{x}}}$ is more equal than that of $\left[h_{2}(!)\right]^{v}$. This process can be continued for all $t$.

When we lower the value of ', keeping all other parameters constant, we basically lower the second term in $(16),\left[\bar{h}_{0}\right]^{\prime}$, while $\left[h_{0}(!)\right]^{v}$ remains unchanged. By Lemma 2 in Karni and Zilcha (1994) we obtain that the distribution of $h_{1}(!)$ becomes less equal. This can be continued for $t=2$ as well since it is easy to verify that $\left[\bar{h}_{1}\right]^{\prime}$ decreases while $\left[h_{1}(!)\right]^{\vee}$ becomes less equal. This process can be extended to $t=2 ; 3 ; \ldots .:$, which complete the proof. $¥$

Proof of Proposition 6. Let us just sketch the proof of this claim. A ny technological improvement, either in the public-component or the homecomponent, will imply higher human capital stock as of period 1 and on. Since, the initial capital stock is given this will increase the output in date 1 and, hence, the aggregate savings in this period. Thus the output in date 2 will be higher and hence the capital stock to be used as well. This process continues in all coming periods. $¥$

\section{R eferences}

Atkinson, A.B., 1970, On the measurement of inequality, J ournal of Economic Theory 2, 244-263.

Atkinson, A.B., 1999, Is rising income inequality inevitable? A critique of the Transatlantic Consensus, UNO/WIDER Publication WAL3. 
Azariadis, C., Drazen, A., 1990, Threshold externalities in economic development, Quarterly J ournal of Economics 105, 501-526.

Becker, G.S., Tomes, N., 1986, Human capital and the rise and fall of families, J ournal of Labor Economics 4(3), S1-39.

Benhabib, J., Farmer, R.E.A., 1994, Indeterminacy and increasing returns, J ournal of Economic Theory 63, 19-41.

Burnhill, P., Garner, C., McPherson, A., 1990, Parental education, social class and entry to higher education 1976-86. J ournal of the Royal Statistical A ssociation, Series A, 153(2), 233-248.

Cardak, B.A., 1999, Heteregeneous preferences, education expenditures and income distribution, The Economic R ecord 75(228), 63-76.

Corneo, G., J eanne, O., 2001, Status, the distribution of wealth, and growth, The Scandinavian J ournal of Economics, 103(2), 283-293.

Eckstein, Z., Zilcha, I, 1994, The exects of compulsory schooling on growth, income distribution and welfare, J ournal of Public Economics 54, 339359.

Eicher, T.S. 1996, Interaction between endogenous human capital and technological change, Review of Economic Studies 63, 127-144.

Fernandez, R ., R ogerson, R ., 1998, P ublic education and income distribution: a quantitative dynamic evaluation of education- ..nance reform, A merican Economic R eview 88(4), 813-833.

Fischer, R.D., Serra, P.J ., 1996, Income convergence within and between countries, International Economic R eview 37(3), 531-551.

Forbes, K.J ., 2000, A reassessment of the relationship between inequality and growth, A merican Economic Review, 90 (4), 865-887.

Galor, O., Moav, 0., 2000, A bility biased technological transition, wage inequality and growth, Quaterly J ournal of Economics 115, 469-497.

Galor, O., Zeira, J ., 1993, Income distribution and macroeconomics, R eview of Economic Studies 60, 35-52.

Glomm, G., Ravikumar, B., 1992, P ublic versus private investment in human capital: endogenous growth and income inequality, J ournal of Political Economy 100, 818-834. 
J ovanovic, B., Nyarko, Y ., 1995, The transfer of human capital, J ournal of Economic Dynamic and Control 19, 1033-1064.

Karni, E., Zilcha, I., 1994, Technological progress and income inequality: A model with human capital and bequests, in: The Changing Distribution of Income in an open US E conomy, eds: Bergstrand et. al., 279-297.

Knight, J ., Shi, L., 1996, Educational attainment and the rural-urban divide in China, Oxford Bulletin of Economics and Statistics 58(1), 83-117.

Lindahl, M., 2001, Home versus school learning: a new approach to estimating the exects of class size on achievement, Discussion Paper No. 261, IZA (Bonn).

Loury, G., 1981, Intergenerational transfers and the distribution of earnings, Econometrica 49(4), 843-867.

Lucas, R., 1988, On the mechanics of economic development, J ournal of M onetary Economics 22, 3-42.

Marrewijk, C. van, 1999, Capital accumulation, learning and endogenous growth, Oxford Economic Papers 51, 453-475.

OECD, 1997, Education at a Glance: OECD Indicators, OECD, Paris. Park, K.H., 1996, Educational expansion and educational inequality on income distribution, Economics of Education R eview 15(1), 51-58.

Persson, T ., Tabellini, G., 1994, Is inequality harmful for growth, A merican Economic R eview 84(3), 600-621.

Shaked, M., Shanthikumar, J.G., 1994, Stochastic Orders and Their A pplications, A cademic Press Inc.

Tamura, R. 1991, Income convergence in an endogenous growth model, J ournal of Political Economy 99, 522-540.

Viaene, J.-M., Zilcha I., 2001, Capital markets integration, growth and income distribution, European Economic R eview, forthcoming. 
Table 1 Baseline and Parameters of the Utility Function*
(1)
(2)
(3)
(4)
(5)
$\mathbb{R}_{1}=\mathbb{R}_{2}=1 \quad \mathbb{B}_{1}=1: 1$
$\mathbb{R}_{2}=1: 1$
$\mathbb{B}_{3}=2: 2$
$\AA_{4}=1: 1$
$\AA_{3}=2$
$\AA_{4}=1$

Relative factor returns

$\left(1+r_{t}\right) \Rightarrow N_{t}$

.471

.471

.504

.442

.492

.451

Gini coeç cient $\left(g_{t}\right)$

.155

.505

.441

.493

.450

Growth rate (\%)

(aggr. output)

.155

.155

.155

.155

.025

.025

.025

.025

Parental education (e)

Poorest agent

28

27.7

28.3

.025

24

28

28

28

31.8

23.9

\section{Richest agent}

.550

.550

.550

32

23.9

_...-.........

.622
.605

.622

.605

.622

.605

.578

.521

$.621 \quad .570$

$*$ Notes: Column (1) is the baseline scenario assuming $i=0: 2 ; \mathbb{R}_{1}=\mathbb{R}_{2}=$ $\mathbb{R}_{4}=1 ; \mathbb{B}_{3}=2 ; \mathrm{A}=4 ; \mu=: 3 ;{ }^{-}{ }_{1}={ }^{-}{ }_{2}=1: 6 ; \grave{A}={ }^{\prime}=1$ : Each row reports the average over the ..rst 10 periods and the average of the second 10 periods. 
Table 2 Baseline and Public Education

$$
\begin{array}{ll}
(1) & (2) \\
i=: 2 & i=: 22
\end{array}
$$

$\begin{array}{lll}\text { Relative factor returns } & .471 & .493 \\ \left(1+r_{t}\right)=N_{t} & .471 & .495 \\ \text { Gini coec cient (g) } & .155 & .145 \\ & .025 & .020 \\ & & \\ \text { Growth rate (\%) } & 28 & 29.7 \\ \text { (aggr. output) } & 28 & 30.1 \\ & & \\ \text { Parental education (e) } & & \\ \text { Poorest agent } & .550 & .543 \\ & .596 & .590 \\ & & \\ \text { Richest agent } & .622 & .616 \\ & .605 & .598\end{array}$




$\begin{array}{llllll}\text { Table } 3 \text { Baseline and Other Speci..cation Externalities } \\ \text { Externalities } & \text { (1) } & \text { (2) } & \text { (3) } & \text { (4) } & \text { (5) } \\ \text { À } & 1 & .9 & 1 & 1.1 & 1 \\ , & 1 & 1 & .9 & 1 & 1.1\end{array}$

\begin{tabular}{|c|c|c|c|c|c|}
\hline Relative factor returns & .471 & .366 & .445 & .816 & .513 \\
\hline$\left(1+r_{t}\right) \Rightarrow N_{t}$ & 471 & 345 & .430 & 3.290 & .581 \\
\hline Gini coeł cient ( $g_{t}$ ) & .155 & .095 & 182 & .288 & .129 \\
\hline (income) & .025 & .003 & .050 & 327 & .008 \\
\hline Growth rate (\%) & 28 & 7.1 & 23.0 & 86.9 & \\
\hline (aggr. output) & 28 & 2.9 & 20.0 & large & 48.1 \\
\hline Parental education ( $\left.e_{t}\right)$ & & & & & \\
\hline Poorest agent & .550 & .550 & .570 & 548 & \\
\hline & .596 & 578 & .621 & .633 & 7 \\
\hline Richest agent & .622 & .598 & .636 & .649 & \\
\hline & .605 & 580 & .632 & .661 & \\
\hline
\end{tabular}


Table $4 \mathrm{~B}$ aseline and Other Speci..cation E $₫$ ciency

$\begin{array}{lllll}\text { E } \phi \text { ciency } & (1) & (2) & (3) & (4) \\ - & & & & \\ -1 & 1.6 & 1.76 & 1.6 & 1.76 \\ 2 & 1.6 & 1.6 & 1.76 & 1.76 \\ \text { Relative factor returns } & .471 & .526 & .482 & .537 \\ \left(1+r_{t}\right)=N_{t} & .471 & .528 & .483 & .540 \\ & & & & \\ \text { Gini coeф cient (gt) } & .155 & .166 & .145 & .155 \\ \text { (income) } & .025 & .031 & .020 & .025 \\ \text { Growth rate (\%) } & 28 & 38.2 & 30.0 & 40.2 \\ \text { (aggr. output) } & 28 & 38.7 & 30.1 & 40.8 \\ & & & & \\ \text { Parental education (e) } & & & & \\ \text { Poorest agent } & .550 & .556 & .543 & .550 \\ & .596 & .601 & .590 & .596 \\ & & & & \\ \text { Richest agent } & .622 & .627 & .616 & .622 \\ & .605 & .612 & .598 & .605\end{array}$


Table 5 Externalities and M edian Voter

\begin{tabular}{|c|c|c|c|c|c|}
\hline Externalities & (1) & (2) & (3) & (4) & (5) \\
\hline \multirow[t]{2}{*}{$\grave{A}$} & 1 & .9 & 1 & 1.1 & 1 \\
\hline & 1 & 1 & .9 & & 1.1 \\
\hline \multirow[t]{2}{*}{ Tax rate $\left(\dot{c}_{\mathrm{t}}\right)$} & .222 & .299 & 109 & 101 & .347 \\
\hline & .203 & .323 & .031 & .019 & .460 \\
\hline \multirow{2}{*}{$\begin{array}{l}\text { Relative factor returns } \\
\left(1+r_{t}\right)=N_{t}\end{array}$} & .496 & .447 & .384 & .684 & .751 \\
\hline & .476 & .440 & .315 & 2.31 & 1.670 \\
\hline \multirow{2}{*}{$\begin{array}{l}\text { Gini coeł cient ( } g \text { ) } \\
\text { (income) }\end{array}$} & .143 & .079 & .213 & .338 & .096 \\
\hline & .021 & . 001 & .127 & .586 & .001 \\
\hline Growth rate (\%) & 30.1 & 12.4 & 9.3 & 80.6 & 52.8 \\
\hline (aggr. output) & 28.6 & 8.5 & 10.3 & large & large \\
\hline \multicolumn{6}{|l|}{ Parental education $\left(\mathrm{e}_{\mathrm{\epsilon}}\right)$} \\
\hline \multirow[t]{2}{*}{ Poorest agent } & .539 & .496 & .602 & .585 & .422 \\
\hline & .595 & .511 & .657 & .641 & .189 \\
\hline \multirow[t]{2}{*}{ Richest agent } & .616 & .556 & .651 & .657 & .519 \\
\hline & .603 & .511 & .662 & .666 & .191 \\
\hline
\end{tabular}


Table $6 \mathrm{E} \pitchfork$ ciency and M edian Voter

$\begin{array}{lllll}\text { E } \phi \text { ciency } & (1) & (2) & (3) & (4) \\ - & & & & \\ -1 & 1.6 & 1.76 & 1.6 & 1.76 \\ 2 & 1.6 & 1.6 & 1.76 & 1.76 \\ \text { Tax rate }\left(i_{t}\right) & & & & \\ & .222 & .188 & .254 & .222 \\ & .203 & .166 & .238 & .203 \\ \text { R elative factor returns } & .496 & .516 & .545 & .565 \\ \left(1+r_{t}\right)=N_{t} & .476 & .490 & .532 & .546 \\ \text { Gini coeф cient (gt) } & .143 & .166 & .124 & .143 \\ \text { (income) } & .021 & .037 & .011 & .021 \\ & & & & \\ \text { Growth rate (\%) } & 30.1 & 37.8 & 35.0 & 42.6 \\ \text { (aggr. output) } & 28.6 & 35.4 & 34.7 & 41.4 \\ & & & & \\ \text { Parental education (e) } & & & & \\ \text { Poorest agent } & .539 & .560 & .517 & .539 \\ & .595 & .611 & .577 & .595 \\ & & & & \\ \text { Richest agent } & .616 & .630 & .600 & .616 \\ & .603 & .622 & .583 & .603\end{array}$

